\title{
Habitat-related variation in reproductive endocrine condition in the coral reef damselfish Acanthochromis polyacanthus
}

\author{
N.W. Pankhurst", Q.P. Fitzgibbon, P.M. Pankhurst and H.R.King \\ School of Aquaculture, Tasmanian Aquaculture and Fisheries Institute, University of \\ Tasmania, Locked Bag 1370, Launceston, Tas 7250, Australia \\ * Corresponding author. Present address: Science, Environment, Engineering and IT \\ Executive, Griffith University, Gold Coast Campus, PMB 50 Gold Coast Mail Centre, \\ Queensland 9726, Australia . \\ E-mail address: n.pankhurst@griffith.edu.au
}

\begin{abstract}
Spiny damselfish Acanthochromis polyacanthis were captured by divers in 1999 and 2001 from reefs around Lizard Island in the northern section of Australia’s Great Barrier Reef, chosen to represent a range of coral cover characteristics. Fish were bled underwater immediately after capture, then blood and fish were placed on ice at the end of the dive for transport to the laboratory where plasma was separated for subsequent measurement of testosterone $(\mathrm{T})$ and 11-ketotestosterone $(11 \mathrm{KT})$ in males, and $\mathrm{T}$ and $17 \beta$-estradiol $\left(E_{2}\right)$ in females. Ovaries from fish captured in 2001 were dispersed to isolate vitellogenic follicles, fecundity and follicle size determined, then follicles were incubated in Leibowitz L15 medium alone or with human chorionic gonadotropin (hCG),
\end{abstract}


to assess steroidogenic capacity. In both 1999 and 2001 there were significant site to site variations in plasma $\mathrm{T}$ and $\mathrm{E}_{2}$ levels in females, and in 2001, in $\mathrm{T}$ and $11 \mathrm{KT}$ in males. Highest hormone levels were recorded from sites of both low, and high coral cover (a measure of presumptive habitat quality), but there was consistently low steroid production in fish from a site of high coral cover and fish density. An initial expectation that poor reproductive condition might be associated with degraded coral sites was not met. Vitellogenic follicles from fish captured in 2001 showed increased in vitro production of $\mathrm{E}_{2}$ and to a lesser extent, $\mathrm{T}$, with increasing follicle size, and this was further augmented by treatment with $\mathrm{hCG}$. Comparison of regression slopes of $\log \mathrm{E}_{2}$ production versus follicle size showed that fish from sites where there were generally low levels of plasma steroids also had impaired in vitro steroidogenic capacity, and that this effect partially disappeared when follicles were stimulated with hCG. Reduced steroidogenic capacity was strongly associated with low fecundity, indicating that low in vitro and in vivo $\mathrm{E}_{2}$ production were reflected in reduced reproductive capacity. As the effect was most consistent at a site where fish density (and subsequent competition for planktonic food) was high, it is suggested that nutritional status associated with habitat characteristics may regulate reproductive endocrine condition in spiny damselfish. It is clear that local factors other than coral cover can generate site variation in reproductive performance.

Keywords: Fish reproduction; Damselfish; Gonadal steroids; In vitro steroidogenesis. 


\section{Introduction}

Coral reefs are highly variable both in terms of taxonomic diversity of the corals that compose them and the form and complexity of their three dimensional structure (Veron, 2000). This in turn creates variability of habitat for coral-dependent fish assemblages, and results in a strong correlation between coral cover and structural complexity, and the diversity and density of reef fishes (reviewed in Bellwood and Wainwright, 2002). The association is particularly strong among pomacentrids (damselfishes), with species number and abundance increasing with spatial complexity of the habitat (Holbrook et al., 2002), the number of hard coral growth forms (Ormond et al., 1996) and the proportion of live corals (Holbrook et al., 2000). Conversely, loss of coral is correlated with falls in the density, diversity and recruitment of pomacentrid species (Booth and Beretta, 2002).

A special case of the coral - pomacentrid relationship is provided by the spiny damselfish Acanthochromis polyacanthus (Bleeker). A. polyacanthus is atypical among reef fishes generally and unique among damselfishes in that there is no larval dispersal phase, but instead hatching juveniles are brooded by both parents and recruit directly onto the natal reef (Thresher, 1983, 1985; Nakazono, 1993). The effect of this is that there is limited capacity for broad scale dispersal and strong evidence for 3 distinct clades along the Great Barrier Reef (GBR), and within each clade, monophyletic assemblages associated with local reef systems (Planes et al., 2001). This means that local densities of A. polyacanthus might be expected to reflect the response of that local population to immediate environmental conditions, rather than being the result of broader scale recruitment events. 
Assessment of population responses to change in habitat quality or characteristic is commonly based on changes in abundance (reviewed in Jones and McCormick, 2002). More subtle changes that will ultimately be reflected in demography but may signal environmental effects on populations at an earlier stage are likely to be found in reproductive performance. Reproductive success is the basic prerequisite for population stability or increase, and is known to be highly sensitive to modulation by both abiotic and biotic aspects of the local environment (eg. Lambert et al., 2000; Pankhurst and Porter, 2003). In tropical systems, these factors include food availability (Knapp, 1995; Izquierdo et al., 2001), parasite load (Adlard and Lester, 1994), density of conspecifics (Petersen and Warner, 2002), temperature variation (Hilder and Pankhurst, 2003), physiological stress (Pankhurst, 2001), and predation intensity (Connell, 1998). Measurement of the effects of these parameters in the field is complicated by the fact that many of them are likely to act synergistically; however, a useful starting point is to assess reproductive characters across spatial scales that encompass a range of habitats and environmental conditions.

Earlier studies on A.polyacanthus from the Cairns sector of the GBR have described endocrine correlates of reproduction in wild fish (Pankhurst et al., 1999), and also established the conditions for further in vitro investigation of ovarian function in fish immediately after collection from the wild (Pankhurst et al., 2000). This work coincided with a period of crown-of-thorns starfish (Acanthaster planci (L.)) invasion, and a marked loss of coral cover from some study sites (Sweatman et al., 1998), raising the question as to whether the change in habitat would be reflected by changes in reproductive endocrine condition, and subsequent reproductive performance. On the 
basis of the strong correlation existing between pomacentrid density and recruitment, and coral cover (Booth and Beretta, 2002), it might be predicted that reproductive performance would be impaired at sites of low, relative to high coral cover. The present study used the combination of understanding of reproductive endocrine function in A.polyacanthus and the opportunity to access sites of low and high coral cover within the same local area of the GBR, to test that prediction.

Accordingly, populations of A. polyacanthus were sampled during the middle of the austral spring peak in spawning during 2 separate years from 4-5 sites on reefs around Lizard Island on the GBR, chosen to cover a range of habitat characteristics, including coral cover. Fish were blood-sampled in situ to provide endocrine correlates of reproduction, and then ovarian tissue was transferred to the laboratory for in vitro assessment of follicular steroidogenic capacity. Endocrine performance and related ovarian development of females were then assessed in relation to habitat.

\section{Materials and Methods}

\subsection{Site characterization, and fish capture and sampling}

Spiny damselfish were captured during the peak spawning period (October to November) in 1999 and 2001 by fence netting as described in Pankhurst et al. (1999), from reefs around Lizard Island in the Lizard Island-Cooktown sector of the GBR. Sampling locations in 1999 were:

1. Mermaid Cove, Lizard Island ( $\left.14^{\circ} 39 \mathrm{~S}, 145^{\circ} 27.2 \mathrm{E}\right)$,

2. North Direction Island $\left(14^{\circ} 44.7 \mathrm{~S}, 145^{\circ} 30.4 \mathrm{E}\right)$, 
3. Eyrie Reef $\left(14^{\circ} 41.3 \mathrm{~S}, 145^{\circ} 30.4 \mathrm{E}\right)$,

4. MacGillivray's Reef $\left(14^{\circ} 38.9 \mathrm{~S}, 145^{\circ} 29.3 \mathrm{E}\right)$,

5. Yonge Reef Bommies $\left(14^{\circ} 35.5 \mathrm{~S}, 145^{\circ} 36.8 \mathrm{E}\right.$ to $\left.14^{\circ} 36.6 \mathrm{~S}, 145^{\circ} 37.2 \mathrm{E}\right)$.

In 2001, time constraints and bad weather restricted sampling to sites $1,2,4$ and 5 . The sampling locations were chosen on the basis of preliminary dive surveys and data from long term reef monitoring surveys (Sweatman et al., 1998) to provide a range of coral cover and types, and fish densities. Site 1 (Mermaid Cove) had low coral cover resulting from extensive predation by Crown-of-thorns starfish in the mid 1990s (Sweatman et al., 1998), with a high proportion of dead coral and coral rubble. Site 2 (North Direction Island) had high coral cover with a mixture of Acropora and substantial Porites colonies. Site 3 (Eyrie Reef) is a shallow patch reef system with a moderate cover of hard coral but dominated by soft coral cover, whereas, MacGillivray's Reef (site 4) is a large sand cay reef with a mixed colony coral community but characterized by large Acropora formosa (Dana) and A. grandis (Brook) colonies at the reef base. Site 5 consists of a series of flattopped bommies located inside the main barrier formation of Yonge Reef and rising from 18-30 $\mathrm{m}$ to within $1-2 \mathrm{~m}$ of the surface at high water. The surfaces of the bommies typically have low profile mixed species communities and there is commonly a ledge or saddle at 6-9 m dominated by Acropora elseyi (Brook) colonies. To confirm the classifications of Sweatman et al. (1998), total coral cover was estimated at each site in 1999 along 50-m transects from the reef crest to the base of the reef at sites 1, 2 and 4 (6$9 \mathrm{~m}$ depth) or the edge of the drop off to deeper water at site 5 (typically 9-12 $\mathrm{m}$ deep). Site 3 is composed of shallow patch reefs (2-6 $\mathrm{m}$ deep at high water) and here transects generally covered the whole extent of the patch reef. The proportion of live coral cover 
directly under the transect tape was measured, and 5 transects were conducted at each site. The same transects in 1999, and additional transects in the same reef areas in 2001, were used to estimate the density of A. polyacanthus. Transects were conducted by 2 divers swimming the length of the tape and conducting a visual census in a notional $10 \mathrm{~m}$ wide strip on their side of the tape. Divers recorded numbers of territorial pairs, and the total numbers of adults present. In 1999 a qualitative estimate of the proportion of pairs holding broods was made on the basis of fish captured for sampling (i.e. only fish targeted for capture were included in the census). In 2001 the proportion of pairs holding broods was counted directly from the transects. Additionally in 2001, total fish density was estimated from video records made at slow swimming speed along the transect tape. All fish present in the field of view were counted from $1 / 2$-speed replays, excluding A.polyacanthus broods.

Immediately after capture, fish were bled underwater by caudal puncture using the technique described in Pankhurst (1990), then killed by brain-spiking. Behaviour of each fish was assessed before capture and classified as described in Pankhurst et al. (1999) as I - non-territorial, II - territory-holding pairs with no visible young, or III - territoryholding pairs brooding young. At the end of the dive, fish and blood samples were placed on ice and returned to the Australian Museum's Lizard Island Research Station for processing. In 1999, diver observation was made of undisturbed territorial pairs of $A$. polyacanthus at each site. A diver positioned 5-10 $\mathrm{m}$ from the nest site recorded the proportion of time that each adult spent 'away' $(>\sim 1 \mathrm{~m})$ from the brood or nest site. Records were accumulated until suitable numbers of pairs defending territories but without broods (behaviour stage II,), and pairs defending broods (behaviour stage III) had 
been recorded at each site ( $\mathrm{n}=3-10$ and $6-14$, respectively). Initial intentions to record the number of chases of other fish entering the territory were abandoned when it was determined that in order to record this accurately, the diver had to be close enough to alter territorial behaviour (Pankhurst et al., 1997).

\subsection{Tissue and blood processing}

At the laboratory, fish were weighed and the length measured, condition factor was calculated as (weight/length $\left.{ }^{3}\right) \times 100$, and gonads excised and macroscopically staged as described in Pankhurst et al. (1999). In 2001, individual ovarian follicles were dispersed in ice cold Leibowitz (L15) culture medium (Sigma) adjusted to 405 mOs.kg ${ }^{-1}$ (Pankhurst et al., 1995), examined using a stereo dissecting microscope to determine the mean maximum dimension $(n=20)$ of the largest vitellogenic oocyte class present, and the total number of vitellogenic follicles present in the ovary. Relative fecundity was determined as number of vitellogenic follicles $\mathrm{g}^{-1}$ body weight. Fecundity measurements were not made in 1999. Follicles were then allocated at 7 per well in 24 -well tissue culture plates (Iwaki) in a final volume of $1 \mathrm{ml} \mathrm{L15}$ medium and incubated for $8 \mathrm{~h}$ at $26^{\circ} \mathrm{C}$ in either $\mathrm{L} 15$ alone, $10 \mathrm{U} \mathrm{ml}^{-1}$ human chorionic gonadotropin (hCG, Sigma) added as $100 \mu 1$ of $100 \mathrm{U} \mathrm{ml}^{-1}$ in $\mathrm{L} 15$, or $100 \mathrm{U} \mathrm{ml}^{-1} \mathrm{hCG}$ added as $100 \mu \mathrm{l}$ of $1000 \mathrm{U} \mathrm{ml}^{-1}$ in L15. HCG doses were chosen on the basis of those shown previously to be effective at stimulating steroidogenesis in spiny damselfish ovarian follicles (Pankhurst et al., 2000). There were 4 replicate wells for each treatment. At the end of the incubation period, media were aspirated into $5 \mathrm{ml}$ polypropylene test tubes and extracted with 3 volumes of ethyl acetate. The ethyl acetate was then aspirated to fresh tubes and dried down in air for 
transport to the University of Tasmania for steroid assay. Blood samples were centrifuged to separate plasma, and $100 \mu \mathrm{l}$ of plasma were then extracted with $1 \mathrm{ml}$ ethyl acetate and dried down for transport as described above.

\subsection{Steroid hormone measurement}

Plasma and media extracts were re-suspended in assay buffer and levels of testosterone $(\mathrm{T})$ and 11-ketotestosterone $(11 \mathrm{KT})$ in males, and $\mathrm{T}$ and $17 \beta$-estradiol $\left(\mathrm{E}_{2}\right)$ in females were measured by RIA using the reagents and protocol described in Pankhurst and Kime (1991) and Pankhurst and Carragher (1992). Inter-assay variability was measured using pooled internal standards for each assay and was (\% CV[n]) 2.2[2], 5.7[4] and 1.0[2] for $\mathrm{E}_{2}, \mathrm{~T}$ and $11 \mathrm{KT}$ respectively in $1999 ; 9.2[2], 6.6[4]$ and 3.6[2] for plasma $\mathrm{E}_{2} \mathrm{~T}$ and $11 \mathrm{KT}$ respectively, and 15.9[7] and 13.4[7] for media $\mathrm{E}_{2}$ and $\mathrm{T}$ respectively in 2001. Assay detection limits were $0.3 \mathrm{ng} \mathrm{ml}^{-1}$ for $\mathrm{T}, \mathrm{E}_{2}$ and $11 \mathrm{KT}$ for plasma in 1999 , $0.15 \mathrm{ng} \mathrm{ml}^{-1}$ for plasma in 2001, and $15 \mathrm{pg} \mathrm{ml}^{-1}$ for $\mathrm{T}_{\text {and }} \mathrm{E}_{2}$ in incubation media. Plasma cortisol levels were also measured in samples from 1999 only. The assay detection was $0.6 \mathrm{ng} \mathrm{ml}^{-1}$ plasma and inter-assay variability (\%CV[n]) was 4.0[4].

\subsection{Statistics}

Changes in coral cover, fish density, fecundity and condition factor by site were analysed by one way ANOVA and subsequent Tukey's b means comparison tests.

Proportions of vitellogenic females at each site were assessed using a $\mathrm{Chi}^{2}$ test. Variation in plasma steroid levels by gonad or behaviour stage were also assessed by ANOVA and Tukey's tests. Analysis of changes in plasma hormone levels by site was conducted as 
above but using data combined by gonad stage according to the outcomes of the analysis of the effect of gonad stage on steroid hormone levels. Where necessary, data were $\log _{10}$ +1 transformed to satisfy requirements for homogeneity of variances, and proportion data were arcsin transformed before analysis. Analyses used a critical value of $\mathrm{P}=0.05$. Hormone values from incubation media were initially plotted against mean maximum follicles size to assess whether steroid production was a function of follicle size, and $1^{\text {st }}$ or $2^{\text {nd }}$ order regressions were fitted to the data. Data were subsequently plotted as $\log -$ normal curves and ANCOVA performed to compare slopes across a truncated data range that ensured that comparisons across sites used data from the same range of follicle sizes (see Results for details). All analyses were conducted using the SPSS for Windows (version 12.1) statistical package.

\section{Results}

\subsection{Coral cover, fish density and reproductive characteristics}

Coral cover surveys conducted in 1999 showed that sites 1 and 3 had lower hard coral cover compared to the other sites, that site 3 was dominated by soft corals and that site 1 had substantially lower total coral cover than the other sites (Table 1). Site 1 in 1999 had lower numbers of adult A. polyacanthus than sites 3,4 and 5, and site 2 had lower numbers than site 4 , but was not different from other sites. In 2001, site 4 had higher numbers of A. polyacanthus than sites 1 and 2 , whereas site 5 was not different from any other site (Table 1). Qualitative assessment of total fish density in 1999 suggested that fish density (all species) was considerably higher at site 5 than at all other sites. Video 
transects conducted in 2001 confirmed this with site 5 having significantly higher fish numbers than the other 3 sites measured in 2001 (Table 1).

Female A. polyacanthus captured at site 2 in 1999 had lower condition factor than fish at all other sites (Table 2). In 2001, the condition factor of females was higher at site 5 than at site 4 but not different from that at sites 1 and 2 (Table 2). There was significant variation in the proportion of vitellogenic females across sites in $1999\left(\mathrm{Chi}^{2}\right.$ value of 16.673, 4 dof. $\mathrm{P}<0.002$ ) with the lowest proportion of vitellogenic fish at Site 5 (Table 2). In 2001, the proportion was again lowest at Site 5 but the difference was not significant (Chi ${ }^{2}$ value of 6.529. 3 dof, $\mathrm{P}<0.09$ ). Relative fecundities varied among sites with fecundity being higher at sites 1 and 3 than at site 5 , and fecundity at site 2 being lower than at site 1, but not different from sites 4 or 5 (Table 2). The qualitative assessment of brood presence conducted in 1999 showed that all sites had evidence of ongoing reproductive activity with $19-44 \%$ of pairs sampled having broods of young (Table 2). In 2001, quantitative assessment showed that again, there was brood presence at all sites, but a lower proportion of pairs at site 5 had broods than pairs at site 1 (Table 2). Behavioural assessment showed that both fish of a nesting pair spent significantly more time away from the territory when young were absent, than when they were present. Analysis of the time fish spent guarding small (less than one month old) vulnerable young showed that there was no detectable behavioral variation across sites (data not shown).

\subsection{Plasma steroid levels}

Plasma $\mathrm{T}$ and $\mathrm{E}_{2}$ levels were elevated in females in 1999 undergoing final oocyte maturation (stage 4) with respect to previtellogenic (stage 2) and vitellogenic (stage 3) 
fish, but there was no significant difference between stages 2 and 3 for either steroid (Fig. 1). Behavioural status had no effect on plasma $T$ or $E_{2}$ level (data not shown). Plasma $T$ and $11 \mathrm{KT}$ levels were elevated in fully spermiated males (stage 3 ) relative to non- (stage 1) or partially spermiated (stage 2) males, which in turn were not different from each other (Fig. 1). Both $\mathrm{T}$ and $11 \mathrm{KT}$ were elevated at stage II relative to other behavioural stages (data not shown). Because gonadal stage affected steroid hormone levels in both males and females, but there was no difference between stages 2 and 3 in females, and stages 1 and 2 in males, site comparisons were made on combined stage 2 and 3 data for females, and combined stage 1 and 2 data for males. Separate analysis of stage 4 females or stage 3 males was not made due to either small sample size, or an absence of these stages from some sites. Females from site 1 (Mermaid Cove), had higher plasma levels of $\mathrm{T}$ and $\mathrm{E}_{2}$ than fish from sites 2 (North Direction), 4 (MacGillivray's Reef) and 5 (Yonge Reef) in 1999 (Fig. 2). There was no effect of site on plasma levels of T or 11KT in males sampled in 1999 (Fig. 2). Plasma cortisol levels were low throughout at all sites in 1999 and were always less than $5 \mathrm{ng} \mathrm{ml}^{-1}$ (data not shown). In 2001, the patterns of plasma $\mathrm{T}$ and $11 \mathrm{KT}$ in males, and $\mathrm{T}$ and $\mathrm{E}_{2}$ in females were similar to 1999 with elevated levels of $\mathrm{T}$ in stage 3 males, and elevated plasma $\mathrm{T}$ and $\mathrm{E}_{2}$ in stage 4 females (Fig. 3). Behavioural stage had no effect on plasma steroid levels in either sex (data not shown). As in 1999, site comparisons in 2001 were restricted to combined stage 1 and 2 male data, and combined stage 2 and 3 female data. Plasma T levels of females were elevated at site 4 relative to sites 1 and 5 , and plasma $\mathrm{E}_{2}$ levels were elevated at site 4 relative to all other sites (Fig. 4). Males showed elevated plasma $\mathrm{T}$ at site 4 relative to site 5 , and elevated plasma $11 \mathrm{KT}$ at site 4 relative to all other sites (Fig. 4). 


\subsection{In vitro steroid production}

$\mathrm{E}_{2}$ production by isolated ovarian follicles was a function of oocyte size, with follicles smaller than $\sim 1.5 \mathrm{~mm}$ producing only small amounts of $\mathrm{E}_{2}$, increasing production occurring at follicle sizes of $1.5-2 \mathrm{~mm}$, and high levels of $\mathrm{E}_{2}$ production from follicles greater than $2 \mathrm{~mm}$ in size. The increase in $\mathrm{E}_{2}$ production with follicle size was best described by $2^{\text {nd }}$ order polynomial regression (Fig. 5). Within this general pattern, there appeared to be reduced responsiveness in follicles from fish at sites 2 (North Direction) and 5 (Yonge Reef) relative to the other 2 sites. This was confirmed by comparison of regression of oocyte size (truncated to include only samples in the $1-2 \mathrm{~mm}$ range where all sites were similarly represented) against $\log \mathrm{E}_{2}$ production (Fig. 6). Basal $\mathrm{E}_{2}$ production increased consistently across the size range of $1-2 \mathrm{~mm}$ in fish from sites 1 and 4, whereas those from sites 2 and $5 \operatorname{did}$ not (ANCOVA $F=3.311, P=0.045)$. Treatment of follicles with hCG resulted in significant increases in $\mathrm{E}_{2}$ in 6/7 fish from site 2 and $5 / 8$ fish from site 5 . In contrast, follicles from only $3 / 9$ fish from site 1 were responsive to hCG and there was no responsiveness to hCG in fish from site 4 (Fig. 5). The significant but generally small increase in $\mathrm{E}_{2}$ production in response to $\mathrm{hCG}$ by follicles from most fish at sites 2 and 5 was sufficient to remove the significant difference between slopes after treatment with hCG $\left(\mathrm{P}=0.135\right.$ and 0.165 for 10 and $100 \mathrm{U} \mathrm{ml}^{-1}$ $\mathrm{hCG}$ respectively). In vitro production of $\mathrm{T}$ showed a similar trend to $\mathrm{E}_{2}$ but with low production until follicles were in excess of $2 \mathrm{~mm}$ in maximum size (data not shown). Because of the relatively flat response in $\mathrm{T}$ production across the follicle size range of 1 $2 \mathrm{~mm}$, regression fits were poor, only site 4 showed an increase in basal T production 
with increasing follicle size, and there was no difference in slope among fish from different sites in terms of the response to either dose of hCG (data not shown).

The slope of $\log$ basal $\mathrm{E}_{2}$ versus oocyte size curve for each site was strongly correlated with relative fecundity, with low (sites 2 and 5) and high (sites 1 and 4) slopes being characterised by low and high relative fecundity respectively (Fig. 7A). There was a less consistent relationship between plasma steroid level and fecundity, with plasma levels of both $\mathrm{T}$ and $\mathrm{E}_{2}$ showing a general increase with fecundity except at the site where the highest fecundity occurred (Fig. 7B).

\section{Discussion}

Coral cover measurements confirmed that the Lizard Island site (Mermaid Cove) had very low coral cover whereas other sites all had moderate to high coral cover, with the proviso that site 3 (Eyrie Reef) was dominated by soft rather than hard corals. The low coral cover at Mermaid Cove reflects the low coral cover at Lizard Island generally, resulting from crown-of-thorns starfish outbreaks from 1996-1998 (Sweatman et al. 1998). Absolute values for coral cover were similar to, or higher than those reported by Sweatman et al.(1998) at 12, 44, 45, 33 and $34 \%$ at sites $1-5$ compared with $<10,17$, 20,17 and $45 \%$ for surveys at the same general locations. The differences probably reflect the more local nature of surveys at each site in the present study, but both studies identify the substantially lower coral cover at site 1 than at other sites.

A. polyacanthus densities measured in 1999 showed a general correlation with coral cover in that there was very low fish density at site 1 where coral cover was low, and 
high and similar densities at sites 3, 4 and 5 where coral cover was high. Site 2 showed high coral cover but only moderate numbers of A. polyacanthus adults. The pattern was similar in 2001 but with an apparent reduction of fish numbers at site 5 . The relatively low numbers of fish at site 2 may result from the fact that coral cover at site 2 was dominated by massive Porites corals that may present less habitat complexity than the other high coral cover sites. Other studies have shown that spatial variation in the structure of fish assemblages can be as strongly related to coral type as to coral cover. For example, 10 out of 14 families (including pomacentrids) showed higher diversity and abundance in habitats with more rugose species of Porites (Holbrook et al., 2002). With this proviso and acknowledging that coral type did vary across sites in the present study, it is clear that the expected relationship between coral cover and density of $A$. polyacanthus is present under conditions of low coral cover.

Assessment of total numbers of fish at each site in 2001 showed that there were greater numbers of fish at site 5 compared with the other 3 sites assessed. As noted above, high fish density is commonly associated with habitat complexity (Ormond et al., 1996; Holbrook et al., 2002; Munday, 2002) and the bommies at site 5 would appear to have the most complex and diverse community structure of all the sites surveyed (Sweatman et al., 1998). An additional factor may relate to the high current flux that typically occurs across the Yonge Reef sites. High current tends to equate with high delivery of zooplankton prey and this is commonly associated with increased abundance and diversity of planktivores in both temperate (Kingsford and MacDiarmid, 1988) and tropical systems (Hobson, 1991). 
The occurrence of low numbers of $A$. polyacanthus at site 1 in the present study was not accompanied by evidence of reduced reproductive activity, with site 1 fish variously showing the highest presence of vitellogenic females, the highest fecundity and the highest proportion of adults holding broods. The lowest values for these parameters were consistently found at site 5 , and to a lesser extent site 2 . This suggests that habitats with low coral cover are not capable of holding large numbers of fish, but the fish that are present show good reproductive condition. In contrast, some sites where there is high coral cover and high fish density appear to show suppressed reproductive performance. Density effects on reproductive performance have been reported in other species, with territorial bluehead wrasse Thalassoma bifasciatum (Bloch) initially showing increased reproductive success as density of conspecifics increases, then falling success as density increases past the point at which males can effectively defend territories (Petersen and Warner, 2002). Whether a similar behavioural effect operates in A. polyacanthus is unclear; however, there were no detectable site-related differences in brooding and guarding behaviour in the present study. This may suggest that source of habitat variation in reproductive performance arises at the level of endocrine control of reproductive development occurs, rather than the capacity to hold a territory and protect young.

Hormonal changes with reproductive development were consistent with those already reported for A. polyacanthus (Pankhurst et al., 1999, 2000) with similar patterns being present in both study years. Females showed elevations in plasma $\mathrm{T}$ and $\mathrm{E}_{2}$ in association with the vitellogenesis and final oocyte maturation. As noted in Pankurst et al. (1999) this is a function of the role of $E_{2}$ in stimulating hepatic synthesis of the yolk precursor vitellogenin during vitellogenesis, and $\mathrm{T}$ as a substrate for $\mathrm{E}_{2}$ synthesis. The high levels of 
$\mathrm{T}$ and $\mathrm{E}_{2}$ in fish undergoing final oocyte maturation are likely to reflect the stimulatory effect of a preovulatory surge of luteinising hormone ( $\mathrm{LH})$ on the multiple vitellogenic clutches generally present in the ovary (Pankhurst et al., 1999). Changes in plasma steroid levels in males were also similar to those described earlier (Pankhurst et al., 1999), with peaks in $\mathrm{T}$ (and in one study year, $11 \mathrm{KT}$ ) occurring in the present study in association with advancing testis development. There is increasing evidence that $11 \mathrm{KT}$ is the primary androgen stimulating spermatogonial proliferation in all teleosts (Schulz et al., 2000) and in the testis of the Japanese eel Anguilla japonica Temminck and Schlegel at least, 11KT is capable of stimulating all stages of spermatogenesis (Miura et al., 1991). $\mathrm{T}$ again appears to have a precursor, rather than direct role in testis development, and its level of elevation in male A. polyacnthus presumably reflects the rate at which it is being converted to other androgens. In common with the earlier work (Pankhurst et al., 1999), males guarding territories without visible young had elevated plasma levels of T in 1999, but this effect was not present in 2001. Elevated T levels are strongly associated with territoriality in a wide range of teleosts and are often highest during the establishment of territory (reviewed in Pankhurst, 2006). The absence of elevated T levels in territorial males in 2001 in the present study may relate to the specific stage in egg guarding at the time of sampling of these fish (eggs are laid deep in coral crevices and are generally not visible to divers undertaking sampling).

Plasma levels of $\mathrm{T}$ and $\mathrm{E}_{2}$ in females were elevated at site 1 in 1999 relative to 3 of the other 4 sites, whereas there was no site effect on male steroids. Female steroid levels were not a function of stage of reproductive development with comparisons being made across equivalent stages of ovarian development, and stage 4 females (fish undergoing final 
oocyte maturation) in which plasma steroid levels can change quite markedly over short periods, not being included in the analysis. In 2001, the pattern was different with high steroid levels at site 4 in both sexes; however, in both study years, plasma steroid levels were lowest at site 5 , in combination with the low proportion of fish undergoing vitellogenesis, and among vitellogenic fish, low fecundity.

At face value, the differing reproductive endocrine states among mature populations at different locations appear to relate to differences in habitat or local conditions, at each of the sites. There is little comparable data in the literature to evaluate this assessment against. Wide scale differences across spawning seasons in factors such as temperature (Onuma et al., 2003), food availability and adult condition (Kurita et al., 2000; Lambert et al., 2000), and anthropogenic influences through pollution (eg. Jardine et al., 1996) are reflected in differences in reproductive performance in a range of species. There is also a large number of studies examining seasonal changes in endocrine correlates within single populations, or fish sampled from single sites (reviewed in Pankhurst, 2007). However, there are very few studies that compare different local populations or sites within and between spawning seasons. An exception is the 5 year assessment of endocrine correlates of reproductive condition and behaviour in the male demoiselle Chromis dispilus Griffin, across sites characterized by different population levels (Pankhurst and Barnett, 1993). Sites of high population density were typified by high levels of reproductive display and territorial interaction and corresponding elevations in plasma levels of $\mathrm{T}, 11 \mathrm{KT}$ and the maturational steroid 17,20ß-dihydroxy-4-pregnen-3-one, in spawning fish. It was concluded that the differences resulted from the social modulation of endocrine status in territory-holding males. The earlier work (Pankhurst and Barnett, 1993) and the present 
study suggest that population or location variability in reproductive endocrine status at equivalent stages of the reproductive cycle may be a common but rarely considered feature of teleost reproduction.

Differences in plasma steroid levels in the present study were mirrored by differential basal in vitro production of $\mathrm{E}_{2}$ by isolated ovarian follicles, with strong correlation between in vitro steroidogenic capacity, and fecundity. The patterns of in vitro steroidogenesis in the present study were essentially similar to those described previously for A. polyacanthus (Pankhurst et al., 2000), with follicles showing consistent basal production of both $\mathrm{T}$ and $\mathrm{E}_{2}$, and further increases in steroid production in response to hCG. HCG acts here as an analogue of the native LH which in teleosts stimulates steroidogenesis through binding with membrane-bound G-protein coupled receptors. This in turn activates adenylate cyclase with subsequent elevation of intracellular levels of cAMP and activation of protein kinases, and the downstream stimulation or synthesis of steroid cleaving enzymes (reviewed in Van Der Kraak and Wade, 1994; Nagahama, 2000). Follicles from fish at sites where fecundity was high showed a size-dependent increase in $E_{2}$ production. There was not a similar relationship between follicle size and $T$ production, presumably as a result of $\mathrm{P}_{450}$ aromatase-mediated conversion of $\mathrm{T}$ to $\mathrm{E}_{2}$. In contrast, at the two sites where plasma steroid levels and fecundity was low, there was essentially no increase in basal $\mathrm{E}_{2}$ production with increasing follicle size. This was only partially offset by treatment with hCG (hCG generated significant increases in $\mathrm{E}_{2}$ production but overall levels were still low), suggesting that fish from sites where follicular seroidogenesis was apparently suppressed may have had reduced plasma LH 
levels, as well as suppression or low activity of the steroidogenic cascade downstream of LH-receptor binding.

The basis for the endocrine suppression observed at some sites in the present study is not known; however, other studies suggest several possibilities with food availability being a leading candidate. In other fish species, there is a clear link between nutritional condition and fecundity, and below a certain level of condition there is typically no maturation (Kurita et al., 2000; Lambert et al. 2000). There is also a well-established link between nutritional status and endocrine condition. Poor nutritional condition results in reduced levels of thyroid hormones (Cerdá-Reverter et al., 1996), and insulin-like growth factors (Baker et al., 2000; Aas-Hansen et al., 2003; Dyer et al., 2004; Reinecke et al., 2005; Small, 2005) in a range of species, and both classes of hormones have permissive or stimulatory effects on reproduction. Tri-iodo-thryonine induces the synthesis of a thyroidhormone induced protein which in turn stimulates the activity of the steroid converting enzyme $3 \beta$-hydroxysteroid dehydrogenase (Datta et al., 1999, 2002). IGF1 increases pituitary synthesis and release of follicle stimulating hormone in coho salmon Oncorhynchus kisutch (Walbaum) (Baker et al., 2000), LH synthesis and release in the European eel Anguilla anguilla L. (Dufour et al., 2000) and sensitivity of the pituitary to gonadotropin releasing hormone in rainbow trout Oncorhynchus mykiss (Walbaum) (Weil et al., 1999). IGF1 can also have permissive effects on the synthesis and action of gonadal steroids (Maestro et al., 1997; Nader et al., 1999) and act directly to stimulate final oocyte maturation (Kagawa et al., 1994; Weber and Sullivan, 2000).

There was insufficient plasma to measure either thyroid hormones or IGF1 levels in the present study but there is a basis for the possibility that fish at some sites (particularly 
site 5) in the present study faced higher food competition than at others. It is well established that assemblages of planktivores accumulate on the upcurrent sides of reefs and that downstream feeding opportunities are reduced as a result of selective removal of larger plankters (Kingsford and MacDiarmid 1988; Hobson 1991). The effect of this will be greater for species that are either constrained by size in terms of their capacity to hold position on the upcurrent margins of the reef, or species such as A. polyacanthus where the demands of territorial protection mean that they have limited capacity to shift their feeding position on the reef. Young A. polyacanthus broods appear to be unprotectable by a single parent (Nakazono 1993), and the results of the present study show that parents of young fish spend very little time away from the nest. Thresher (1983) demonstrated experimentally that reproductive success of A. polyacanthus is affected by competition for food. A. polyacanthus from reefs that had planktivores cleared from them had larger broods than fish on unmanipulated reefs, and if all fish were removed, spawning occurred earlier and juvenile survival was increased. An effect of this type would have been most severe in the present study at site 5 , where overall fish (and planktivore) density was highest. Fish from site 5 in the present study did not have smaller size or lower condition factor from other sites; however, the critical issue in determining reproductive success appears to be the nature of the nutrient reserve rather than absolute size or condition. Increased dietary lipid, particularly highly unsaturated fatty acids has been shown to increase fecundity in rabbitfish Siganus guttatus (Bloch) and gilthead seabream Sparus auratus L. (Izquierdo et al. 2001), and supplementary feeding of the territorial pomacentrid Stegastes partitus (Poey) with beef fat substantially increased courtship activity (Knapp 1995). Significantly, fed males in that study had an increased proportion 
of body fat but no difference in weight or length from unfed fish. Similar uncoupling of size and condition factor from energetic status has also been described in fathead minnow Pimephales promelas Rafinesque, and three spined stickleback Gasterosteus aculeatus L. (Unger, 1983; Fitzgerald et al., 1989).

Another factor that can suppress reproductive performance is physiological stress, with clear evidence that artificial imposition of stress through activities such as capture and handling generates a rapid and profound inhibition of most aspects of reproduction in a wide range of species including A. polyacanthus (Pankhurst, 2001). Plasma cortisol levels are commonly used as a primary indicator of exposure to stress and were measured in the present study in 1999. Cortisol levels were low throughout $\left(<5 \mathrm{ng} \mathrm{ml}^{-1}\right)$ and well below the values (typically in excess of $30 \mathrm{ng} \mathrm{ml}^{-1}$ ) found in fish exposed to confinement (and where there is rapid suppression of reproductive steroids; Pankhurst, 2001). This suggests that the reproductive suppression seen at some sites in the present study did not result from physiological stress in terms of our current understanding of conditions under which stress inhibition of reproduction occurs.

The present study shows that there can be location or habitat variation in reproductive performance in A. polyacanthus. Contrary to initial expectations, the lowest levels of reproductive output were not found at sites with highly degraded coral, but at a site with high coral cover and fish density and diversity. This suggests that provided there is suitable structural cover for nesting and territory protection, habitats with low coral cover (and correspondingly low density of conspecifics and other species) may offer better opportunities for reproductive development than high coral cover, high fish density sites where competitive interactions are likely to be more intense. It is clear that reproductive 
performance in this species of damselfish is not simply a function of the extent of coral cover.

\section{Acknowledgments}

This study was supported by an Australian Research Council Large Grant awarded to NWP. Thanks are extended to the staff at the Australian Museum's Lizard Island Research Station for infrastructure and operational support, and to Catriona MacLeod and Mark Hilder for assistance with some of the field work. Procedures reported here were conducted under permit approval from the Great Barrier Reef Marine Park Authority, Queensland Fisheries Management Authority and the University of Tasmania Animal Ethics Committee.

\section{References}

Aas-Hansen, O., Johnsen, H.K., Vijayan, M.M., Jørgensen, E.H., 2003. Development of seawater tolerance and concurrent hormonal changes in fed and fasted Arctic charr at two temperature regimes. Aquaculture 222, 135-148.

Adlard, R.D., Lester, R.J.G., 1994. Dynamics of the interaction between the parasitic isopod, Anilocra pomacentri, and the coral reef fish, Chromis nitida. Parasitology 109, 311-324.

Baker, D.M., Davies, B., Pierce, A.L., Dickhoff, W.W., Swanson, P., 2000. Effects of fasting and metabolic hormones on the reproductive axis of coho salmon, Oncorhynchus kisutch. In: Norberg, B., Kjesbu, O.S., Taranger, G.L., Andersson, 
E., Stefansson S.O.(Eds.), Proceedings of the $6^{\text {th }}$ International Symposium on the Reproductive Physiology of Fish. John Grieg A/S, Bergen, pp. 478-480.

Bellwood, D.R., Wainwright, P.C., 2002. The history and biogeography of fishes on coral reefs. In: Sale, P.F. (Ed.), Coral Reef Fishes: Dynamics and Diversity in a Complex Ecosystem. Academic Press, San Diego, pp. 5-32.

Booth, D.J., Beretta, G.A., 2002. Changes in a fish assemblage after a coral bleaching event. Mar. Ecol. Prog. Ser. 245, 205-212.

Cerdá-Reverter, J.M., Zanuy, S., Carrillo, M., Kah, O., 1996. Development of enzyme immunoassays for 3,5,3'-triiodo-L-thyronine and L-thyroxine: Time-course studies on the effect of food deprivation on plasma thyroid hormones in two marine teleosts, sea bass (Dicentrarchus labrax L.) and sea bream (Sparus aurata L.). Gen. Comp. Endocrinol. 103, 290-300.

Connell, S.D.,1998. Effects of predators on growth, mortality and abundance of a juvenile reef-fish: Evidence from manipulations of predator and prey abundance. Mar. Ecol. Prog. Ser. 169, 251-261.

Datta, M., Nagendra Prasad, R.J., Bhattacharya, S., 1999. Thyroid hormone regulation of perch ovarian $3 \beta$-hydroxysteroid dehydrogenase $/ \Delta^{5}-\Delta^{4}$-isomerase activity: involvement of a 52-kDa protein. Gen. Comp. Endocrinol. 113, 212-220.

Datta, M., Prasad, R.J.N., Navneet, A.K., Roy, S.S., Bhattacharya, S., 2002. Thyroid hormone-induced protein (TIP) gene expression by 3,5,3'-triiodothyronine in the ovarian follicle of perch (Anabas testudineus, Bloch): modulation of $3 \beta-$ hydroxysteroid dehydrogenase $/ \Delta^{4}-\Delta^{5}$-isomerase enzyme by TIP. Gen. Comp. Endocrinol. 126, 334-341. 
Dufour, S., Huang, Y.S., Rousseau, K., Sbaihi, M., Le Belle, N., Vidal, B., Marchelidon,J., Quérat, B., Burzawa-Gérard, E., Chang, C.F., Schmitz, M., 2000. Puberty in teleosts: New insights into the role of peripheral signals in the stimulation of pituitary gonadotropins. In: Norberg, B., Kjesbu, O.S., Taranger, G.L., Andersson, E., Stefansson, S.O. (Eds.), Proceedings of the $6^{\text {th }}$ International Symposium on the Reproductive Physiology of Fish. John Grieg A/S, Bergen, pp. $455-461$.

Dyer, A.R., Upton, Z., Stone, D., Thomas, P.M., Soole, K.L., Higgs, N., Quinn, K., Carragher, J.F., 2004. Development and validation of a radioimmunoassay for fish insulin-like growth factor I (IGF-I) and the effects of aquaculture related stressors on circulating IGF-I levels. Gen. Comp. Endocrinol. 135, 268-275.

Hilder, M.L., Pankhurst, N.W., 2003. Evidence that temperature change cues reproductive development in the spiny damselfish, Acanthochromis polyacanthus. Env. Biol. Fishes 66, 187-196.

Hobson, E.S., 1991. Trophic relationships of fishes specialized to feed on zooplankters above coral reefs. In: Sale, P.F. (Ed.), The Ecology of Coral Reef Fishes. Academic Press, San Diego, pp. 69-95.

Holbrook, S.J., Forrester, G.E., Schmitt, R.J., 2000. Spatial patterns in abundance of a damselfish reflect availability of suitable habitat. Oecologia 122, 109-120.

Holbrook, S.J., Brooks, A.J., Schmitt, R.J., 2002. Variation in structural attributes of patch-forming corals and in patterns of abundance of associated fishes. Mar. Freshwat. Res. 53, 1045-1054. 
Izquierdo, M.S., Fernández-Palacios, H., Tacon, A.G.J., 2001. Effect of broodstock nutrition on reproductive performance of fish. Aquaculture 197, 25-42.

Jardine, J.J., Van Der Kraak, G.J., Munkittrick, K.R., 1996. Capture and confinement stress in white sucker exposed to bleached kraft pulp mill effluent. Ecotoxicol. Env. Safety 33, 287-298.

Jones, G.P., McCormick, M.I., 2002. Numerical and energetic processes in the ecology of coral reef fishes. In: Sale, P.F. (Ed.),Coral Reef Fishes: Dynamics and Diversity in a Complex Ecosystem. Academic Press, San Diego, pp. 221-238.

Kagawa, H., Kobayashi, M., Hasegawa, Y., Aida, K., 1994. Insulin and insulin-like growth factors I and II induce final maturation of oocytes of red seabream, Pagrus major, in vitro. Gen. Comp. Endocrinol. 95, 293-300.

Kingsford, M.J., MacDiarmid, A.B., 1988. Interrelationships between planktivorous reef fish and zooplankton in temperate waters. Mar. Ecol. Prog. Ser. 48, 103-117.

Knapp, R.A., 1995. Influence of energy reserves on the expression of a secondary sexual trait in male bicolor damselfish, Stegastes partitus. Bull. Mar. Sci. 57, 672-681.

Kurita, Y., Thorsen, A., Fonn, M., Svardal, A., Kjesbu, O.S., 2000. Oocyte growth and fecundity regulation of Atlantic herring (Clupea harengus) in relation to declining body reserves during overwintering. In: Norberg, B., Kjesbu, O.S., Taranger, G.L., Andersson, E., Stefansson, S.O. (Eds.), Proceedings of the $6^{\text {th }}$ International Symposium on the Reproductive Physiology of Fish. John Grieg A/S, Bergen, pp. $85-87$.

Lambert, Y., Dutil, J-D., Ouellet, P., 2000. Nutritional condition and reproductive success in wild fish populations. In: Norberg, B., Kjesbu, O.S., Taranger, G.L., 
Andersson, E., Stefansson, S.O. (Eds.), Proceedings of the $6^{\text {th }}$ International Symposium on the Reproductive Physiology of Fish. John Grieg A/S, Bergen, pp. $77-84$.

Maestro, M.A., Planas, J.V., Moriyama, S., Gutiérrez, J., Planas, J., Swanson, P., 1997. Ovarian receptors for insulin and insulin-like growth factor I (IGF-I) and effects of IGF-I on steroid production by isolated ovarian follicular layers of the preovulatory coho salmon ovarian follicle. Gen. Comp. Endocrinol. 106, 189201.

Miura, T., Yamauchi, K., Takahashi, H., Nagahama, Y., 1991. Hormonal induction in vitro of all stages of spermatogenesis in the male Japanese eel (Anguilla japonica). Proc. Nat. Acad. Sci. USA 88, 5774-5778.

Munday, P.L., 2002. Does habitat availability determine geographical-scale abundances of coral-dwelling fishes? Coral Reefs 21, 106-116.

Nader, M.R., Miura, T., Ando, N., Miura, C., Yamauchi, K., 1999. Recombitant human insulin-like growth factor I stimulates all stages of 11-ketotestosterone-induced spermatogenesis in the Japanese eel, Anguilla japonica, in vitro. Biol. Reprod. 61, 944-947.

Nagahama, Y., 2000. Gonadal steroid hormones: Major regulators of gonadal sex differentiation and gametogenesis in fish. In: Norberg, B., Kjesbu, O.S., Taranger, G.L., Andersson, E., Stefansson, S.O. (Eds.), Proceedings of the $6^{\text {th }}$ International Symposium on the Reproductive Physiology of Fish. John Grieg A/S, Bergen, pp. 211-222. 
Nakazono, A.. 1993. One-parent removal experiment in the brood-caring damselfish, Acanthochromis polyacanthus, with preliminary data on reproductive biology. Aust. J. Mar. Freshwat. Res. 44, 699-707.

Onuma, T. Higashi, Y., Ando, H., Ban, M., Ueda, H., Urano, A., 2003. Year-to-year differences in plasma levels of steroid hormones in pre-spawning chum salmon. Gen. Comp. Endocrinol. 133, 199-215.

Ormond, R.F.G., Roberts, J.M., Jan. R-Q.,1996. Behavioral differences in microhabitat use by damselfishes (Pomacentridae): implications for reef fish biodiversity. J. Exp. Mar. Biol. Ecol. 202, 85-95.

Pankhurst, N.W., 1990. Changes in plasma levels of gonadal steroids during spawning behaviour in territorial male demoiselles Chromis dispilus (Pisces: Pomacentridae) sampled underwater. Gen. Comp. Endocrinol.79, 215-225.

Pankhurst, N.W., 2001. Stress inhibition of reproductive endocrine processes in a natural population of the spiny damselfish Acanthochromis polyacanthus. Mar. Freshwat. Res. 52, 753-761.

Pankhurst, N.W., 2007. Gonadal steroids: functions and patterns of change. In: Rocha, M.J., Arukwe, A., Kapoor, B.G. (Eds.), Fish Reproduction: Cytology, Biology and Ecology. Science Publisher Inc., Enfield, New Hampshire, in press.

Pankhurst, N.W., Barnett, C.W., 1993. Relationship of population density, territorial interaction and plasma levels of gonadal steroids in spawning male demoiselles Chromis dispilus (Pisces: Pomacentridae). Gen. Comp. Endocrinol. 90, 168176. 
Pankhurst, N.W., Carragher, J.F., 1992. Oocyte maturation and changes in plasma steroid levels in snapper Pagrus (=Chrysophrys) auratus (Sparidae) following treatment with human chorionic gonadotropin. Aquaculture 101, 337-347.

Pankhurst, N.W., Kime, D.E., 1991. Plasma sex steroid levels in male blue cod Parapercis colias (Bloch and Schneider)(Pinguipedidae) sampled underwater during the spawning season. Aust. J. Mar. Freshwat. Res. 42, 129-137.

Pankhurst, N.W., Porter, M.J.R., 2003. Cold and dark or warm and light: Variations on the theme of environmental control of reproduction. Fish Physiol. Biochem. 28, 385-389.

Pankhurst, N.W., Van Der Kraak, G., Peter, R.E., 1995. Evidence that the inhibitory effects of stress on reproduction in teleost fish are not mediated by the action of cortisol on ovarian steroidogenesis. Gen. Comp. Endocrinol. 99, 249-257.

Pankhurst, N.W., Barnett, C.W., Butler, P.I., Pankhurst, P.M., Hobby, A.C., 1997. Environmental disturbance, reproductive behaviour and plasma steroid levels in the spiny damselfish Acanthochromis polyacanthus. In: Kawashima, S., Kikuyama, S. (Eds.), Advances in Comparative Endocrinology. Monduzzi Editore, Bologna, pp. 1707-1713.

Pankhurst, N.W., Hilder, P.I., Pankhurst, P.M., 1999. Reproductive condition and behavior in relation to plasma levels of gondal steroids in the spiny damselfish Acanthochromis polyacanthus. Gen. Comp. Endocrinol. 115, 53-69.

Pankhurst, N.W., Pankhurst, P.M., Hilder, P.I., Hilder, M.L., 2000. In vivo and in vitro ovarian steroid production by fish from a natural population of the brooding tropical damselfish Acanthochromis polyacanthus. In: Norberg, B., Kjesbu, O.S., 
Taranger, G.L., Andersson, E., Stefansson, S.O. (Eds.), Proceedings of the $6^{\text {th }}$ International Symposium on the Reproductive Physiology of Fish. John Grieg A/S, Bergen, pp. 99-102.

Petersen, C.W., Warner, R.R., 2002. The ecological context of reproductive behavior. In: Sale, P.F. (Ed.), Coral Reef Fishes: Dynamics and Diversity in a Complex Ecosystem. Academic Press, San Diego, pp. 103-122.

Planes, S., Doherty, P.J., Bernard, G., 2001. Strong genetic divergence among populations of a marine fish with limited dispersal, Acanthochromis polyacanthus, within the Great Barrier Reef and the Coral Sea. Evolution 55, 2263-2273.

Reinecke, M., Björnsson, B.T., Dickhoff, W.W., McCormick, S.D., Navarro, I., Power, D.M., Gutiérrez, J., 2005. Growth hormone and insulin-like growth factors in fish: Where we are and where to go. Gen. Comp. Endocrinol. 142, 20-24.

Schulz, R.W., Bogerd J., Goos, H.J. Th., 2000. Spermatogenesis and its endocrine regulation. In: Norberg, B., Kjesbu, O.S., Taranger, G.L., Andersson, E., Stefansson, S.O. (Eds.), Proceedings of the $6^{\text {th }}$ International Symposium on the Reproductive Physiology of Fish. John Grieg A/S, Bergen, pp. 225-232.

Small, B.C., 2005. Effect of fasting on nychthemeral concentrations of plasma growth hormone (GH), insulin-like growth factor I (IGF-I), and cortisol in channel catfish (Ictalurus punctatus). Comp. Biochem. Physiol. 142B, 217-223.

Sweatman, H., Bass, D., Cheal, A., Coleman, G., Miller, I., Ninio, R., Osborne, K., Oxley, W., Ryan, D., Thompson, A., Tompkins, P., 1998. Long-term Monitoring 
of the Great Barrier Reef: Status Report Number 3. Australian Institute of Marine Science, Townsville, 303p.

Thresher, R.E., 1983. Habitat effects on reproductive success in the coral reef fish, Acanthochromis polyacanthus (Pomacentridae). Ecology 64, 1184-1199.

Thresher, R.E., 1985. Distribution abundance and reproductive success in the coral reef fish Acanthochromis polyacanthus. Ecology 66, 1139-1150.

Unger, L.M., 1983. Nest defense by deceit in the fathead minnow, Pimephales promelas. Behav. Ecol. Sociobiol. 13, 125-130.

Van Der Kraak, G., Wade, M.G., 1994. A comparison of signal transduction pathways mediating gonadotropin actions in vertebrates. In:. Davey, K.G., Peter, R.E., Tobe, S.S. (Eds.), Perspectives in Comparative Endocrinology. National Research Council of Canada, Ottawa, pp. 56-93.

Veron, J.E.N. (2000). Corals of the World, Volume 1. Australian Institute of Marine Science, Townsville, 463p.

Weber, G.M., Sullivan, C.V., 2000. Effects of insulin-like growth factor-I on in vitro final oocyte maturation and ovarian steroidogenesis in striped bass, Morone saxatilis. Biol. Reprod. 63, 1049-1057.

Weil, C., Carré, F., Blaise, O., Breton, B., Le Bail, P-Y.,1999. Differential effect of insulin-like growth factor I on in vitro gonadotropin (I and II) and growth hormone secretions in rainbow trout (Oncorhynchus mykiss) at different stages of the reproductive cycle. Endocrinology 140, 2054-2062. 
Table 1. Coral cover (\%) at Mermaid Cove (Site 1), North Direction Island (Site 2), Eyrie Reef (Site 3), MacGillivray’s Reef (Site 4) and Yonge Reef (Site 5) in 1999; and relative density (number per transect) of A. polyacanthus adults (1999 and 2001), and all species (2001).

\section{Site}

1

2

3

\section{Coral Cover ${ }^{1}$}

Hard coral

Soft coral

Total coral cover

$\begin{array}{ccc}12.9 \pm 1.9^{\mathrm{a}} & 40.1 \pm 4.8^{\mathrm{b}} & 13.3 \pm 3.1^{\mathrm{a}} \\ 0^{\mathrm{a}} & 2.6 \pm 2.3^{\mathrm{a}} & 31.3 \pm 4.2^{\mathrm{b}} \\ 12.2 \pm 1.9^{\mathrm{a}} & 42.7 \pm 6.5^{\mathrm{b}} & 44.9 \pm 5.9^{\mathrm{b}}\end{array}$

$28.1 \pm 3.0^{\mathrm{b}}$

$28.1 \pm 3.5^{\mathrm{b}}$

$6.3 \pm 1.6^{\mathrm{a}}$

$6.0 \pm 1.9^{\mathrm{a}}$

Fish Density ${ }^{1}$

A. polyacanthus (1999)

$6.0 \pm 2.0^{\mathrm{a}} \quad 16.2 \pm 1.7^{\mathrm{ab}}$

$25.8 \pm 7.2^{\mathrm{bc}}$

$34.5 \pm 3.3^{\mathrm{b}}$

$34.1 \pm 3.0^{\mathrm{b}}$

A. polyacanthus (2001)

$6.5 \pm 2.2^{\mathrm{a}}$

$15.1 \pm 3.8^{\mathrm{a}}$

n.m

$35.6 \pm 5.4^{\mathrm{c}}$

$27.0 \pm 4.9^{\mathrm{bc}}$

All species (2001)

$102 \pm 9^{a}$

$131 \pm 15^{\mathrm{a}}$

n.m

$29.1 \pm 4.5^{b}$

$16.9 \pm 3.4^{\mathrm{ab}}$

$142 \pm 15^{\mathrm{a}}$

$223 \pm 26^{\mathrm{b}}$

${ }^{1}$ Values are mean $\pm \mathrm{SE}(\mathrm{n}=5,50 \mathrm{~m}$ transects per site for coral cover, and 5-7 transects for fish density). Common superscripts show values that are not significantly different $(\mathrm{P}>0.05)$. N.m $=$ not measured. 
Table 2. Condition factor, proportion of females showing vitellogenic development, and proportion of adult pairs with broods in fish captured at sample sites ${ }^{1}$ in 1999 and 2001.

\begin{tabular}{|c|c|c|c|c|c|}
\hline & \multicolumn{4}{|c|}{ Site } & \multirow[b]{2}{*}{5} \\
\hline & 1 & 2 & 3 & 4 & \\
\hline \multicolumn{6}{|c|}{ Condition factor ${ }^{2}$} \\
\hline 1999 & $3.07 \pm 0.05(17)^{b}$ & $2.81 \pm 0.04(16)^{\mathrm{a}}$ & $3.04 \pm 0.03(24)^{b}$ & $3.18 \pm 0.12(15)^{b}$ & $3.07 \pm 0.07(18)^{b}$ \\
\hline 2001 & $2.90 \pm 0.04(15)^{\mathrm{ab}}$ & $2.90 \pm 0.05(27)^{\mathrm{ab}}$ & n.m & $2.85 \pm 0.06(18)^{\mathrm{a}}$ & $3.02 \pm 0.03(37)^{b}$ \\
\hline \multicolumn{6}{|c|}{$\begin{array}{l}\text { Proportion of } \\
\text { vitellogenic females }^{3}\end{array}$} \\
\hline 1999 & 0.75 & 0.40 & 0.70 & 0.35 & $0.18^{*}$ \\
\hline 2001 & 0.64 & 0.43 & n.m & 0.61 & 0.30 \\
\hline \multicolumn{6}{|c|}{ Fecundity $^{4}$} \\
\hline 2001 & $10.1 \pm 1.2(7)^{\mathrm{c}}$ & $5.2 \pm 1.0(9)^{\mathrm{ab}}$ & n.m & $7.8 \pm 1.1(11)^{b c}$ & $3.8 \pm 0.4(8)^{\mathrm{a}}$ \\
\hline \multicolumn{6}{|c|}{ Proportion pairs with } \\
\hline \multicolumn{6}{|c|}{ broods } \\
\hline $1999^{5}$ & 0.57 & 0.21 & 0.50 & 0.34 & 0.38 \\
\hline $2001^{6}$ & $0.56 \pm 0.21(6)^{b}$ & $0.29 \pm 0.13(6)^{\mathrm{ab}}$ & n.m & $0.35 \pm 0.09(6)^{\mathrm{ab}}$ & $0.11 \pm 0.05(7)^{\mathrm{a}}$ \\
\hline
\end{tabular}

${ }^{1}$ Sample sites as in Table 1

${ }^{2}$ Values are mean $\pm \mathrm{SE}(\mathrm{n})$. Throughout, common superscripts indicate values that are not significantly different $(\mathrm{P}>0.05)$.

${ }^{3}$ Proportion of adult females with vitellogenic ovarian follicles. * Significant difference in proportion across sites $\left(\mathrm{Chi}{ }^{2}\right.$ test, $\left.\mathrm{P}<0.05\right)$.

${ }^{4}$ Values are mean \pm SE (n) [vitellogenic follicles. $\mathrm{g}^{-1}$ body weight]

${ }^{5}$ Qualitative assessment only - see text for details.

${ }^{6}$ Values are mean $\pm \mathrm{SE}$ ( $\mathrm{n}=$ number of $50 \mathrm{~m}$ transects). 


\section{Captions for figures}

Fig. 1. Plasma levels of testosterone $(\mathrm{T})$ and $17 \beta$-estradiol $\left(\mathrm{E}_{2}\right)$ in relation to ovarian stage $(2=$ previtellogenic, 3 = vitellogenic, $4=$ undergoing final oocyte maturation) in female, and T and 11ketotestosterone $(11 \mathrm{KT})$ in relation to testis stage $(1=$ non-spermiated, $2=$ partially spermiated, $3=$ fully spermiated) in male spiny damselfish captured in 1999. Values are mean + SE (n). Values with common superscripts are not significantly different $(\mathrm{P}>0.05)$.

Fig. 2. Plasma levels of $\mathrm{T}$ and $\mathrm{E}_{2}$ in females, and $\mathrm{T}$ and $11 \mathrm{KT}$ in males, in relation to site $(1=$ Mermaid Cove, 2 = North Direction Island, 3 = Eyrie Reef, 4 = MacGillivray’s Reef, 5 = Yonge Reef bommies) in 1999. Male data are gonad stages 1 and 2 combined; female data are gonad stages 2 and 3 combined. Other details as for Fig. 1.

Fig. 3. Plasma levels of $\mathrm{T}$ and $\mathrm{E}_{2}$ in females, and $\mathrm{T}$ and $11 \mathrm{KT}$ in males, in relation to gonad stage in spiny damselfish captured in 2001. Other details as for Fig. 1.

Fig. 4. Plasma levels of $\mathrm{T}$ and $\mathrm{E}_{2}$ in females, and $\mathrm{T}$ and $11 \mathrm{KT}$ in males, and in relation to site in 2001. Other details as for Figs. 1 and 2.

Fig. 5. In vitro $\mathrm{E}_{2}$ production by isolated ovarian follicles from spiny damselfish captured in 2001 from Sites 1,2,4 and 5 (see Fig.2 for details) following incubation in L15 medium alone (basal), or L15 supplemented with 10 or $100 \mathrm{U}_{\mathrm{m}} \mathrm{ml}^{-1}$ human chorionic gonadotropin ( $\mathrm{hCG}_{10}$ and $\mathrm{hCG}_{100}$ respectively), in relation to mean maximum follicle dimension. Curve fits are $2^{\text {nd }}$ order polynomials. Each value is 
the mean of 4 incubation wells. Fraction on each panel is proportion of fish showing responsiveness to $\mathrm{hCG}$ (single asterisk $=$ significant effect of $\mathrm{hCG}$ at $100 \mathrm{U} \mathrm{ml}^{-1}$; double asterisk $=$ significant effect of hCG at 10 and $100 \mathrm{U} \mathrm{ml}^{-1}$ ).

Fig. 6. Linear regression of mean maximum follicle size on $\log$ basal $\mathrm{E}_{2}$ production in vitro (site and treatment details as for Fig. 5). Slopes for basal production differ significantly (see text for details) whereas those for $\mathrm{hCG}_{10}$ and $\mathrm{hCG}_{100}$ do not.

Fig.7. Relationship of a) slope of regression of follicle size on log basal $E_{2}$ production and b) plasma level of $\mathrm{T}$ and $\mathrm{E}_{2}$, and relative fecundity in vitellogenic fish captured from different sites (site descriptions as in Fig. 2) in 2001. Plasma steroid values are the mean for all vitellogenic females at that site. 


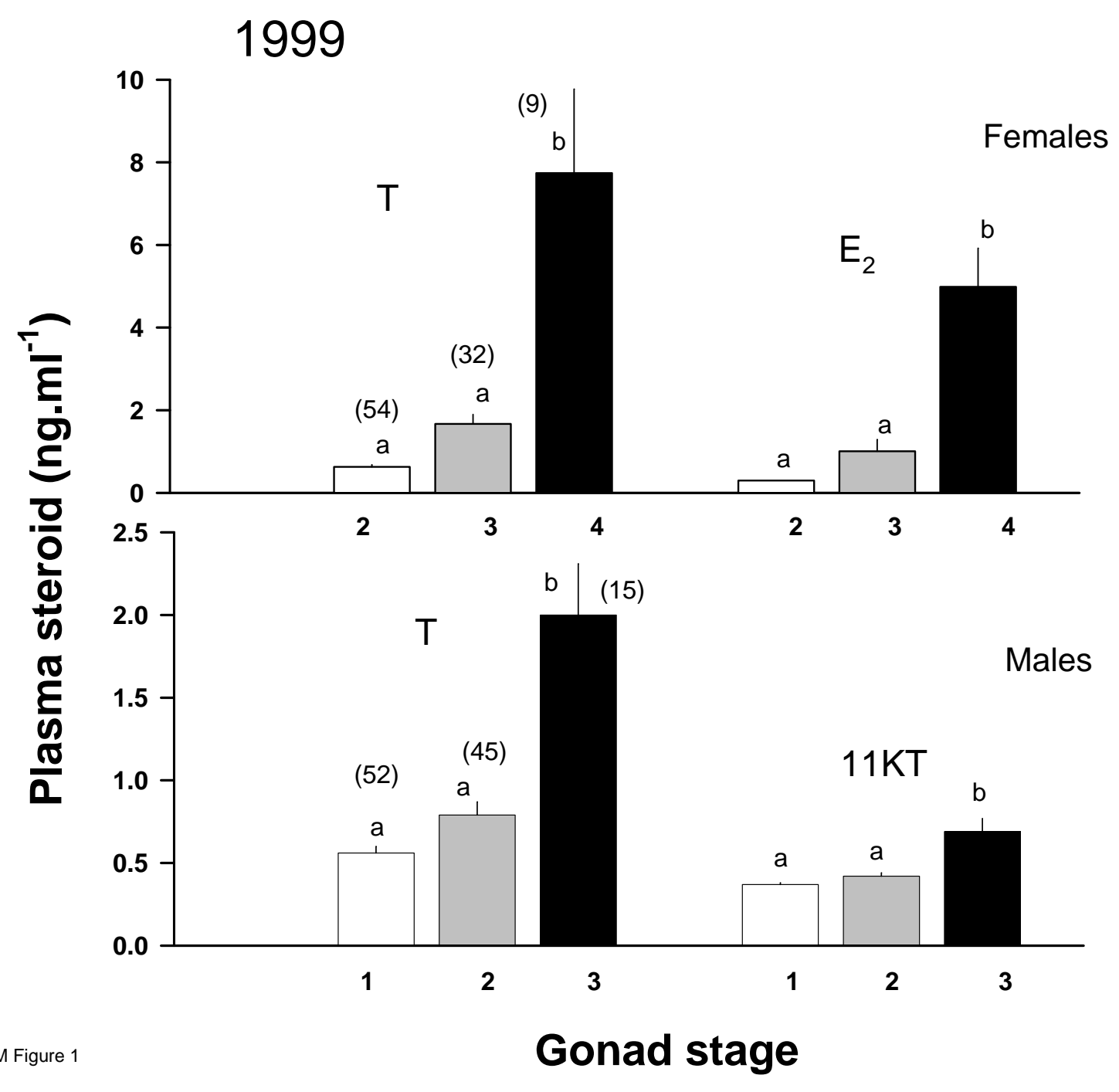




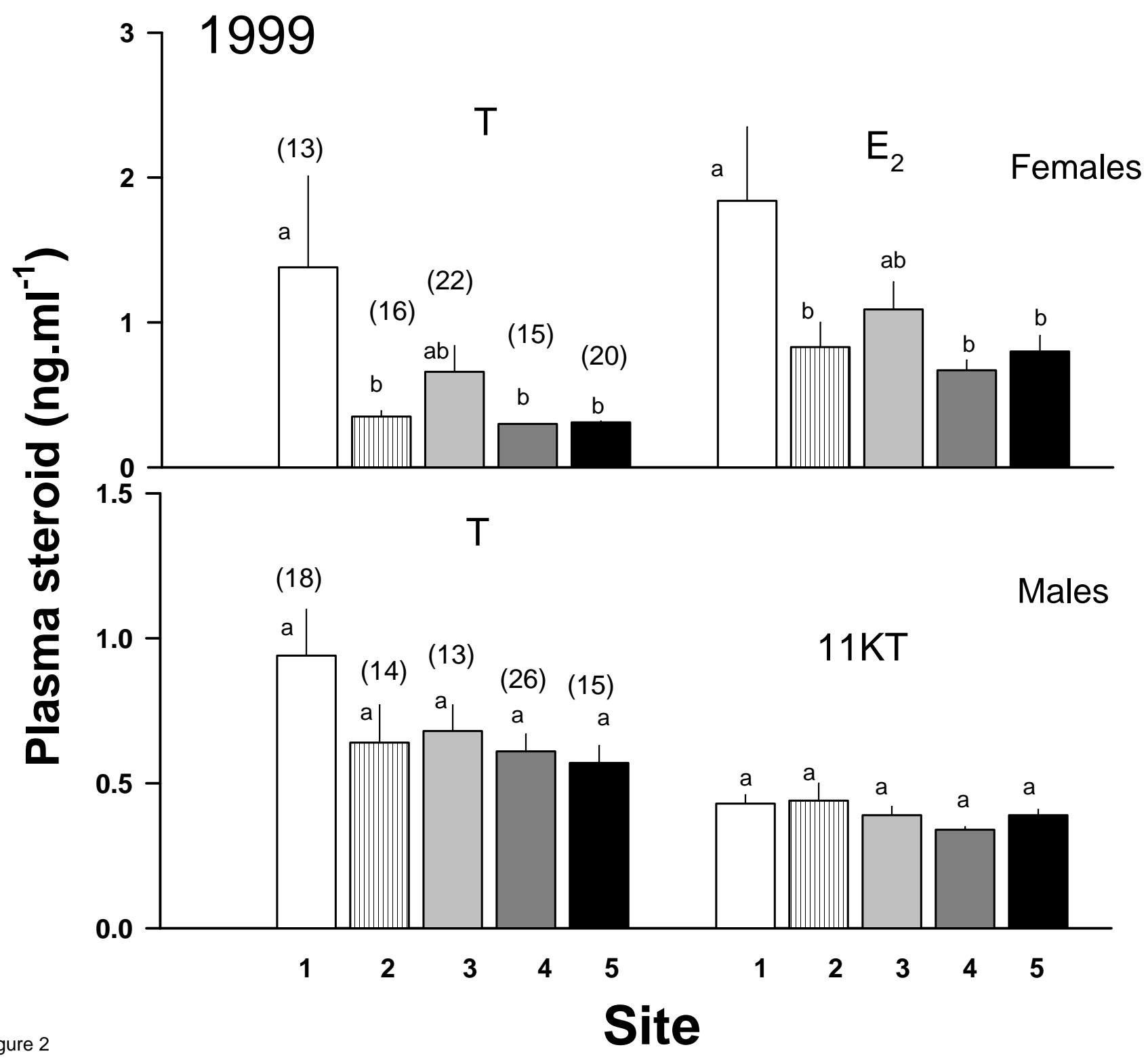


2001

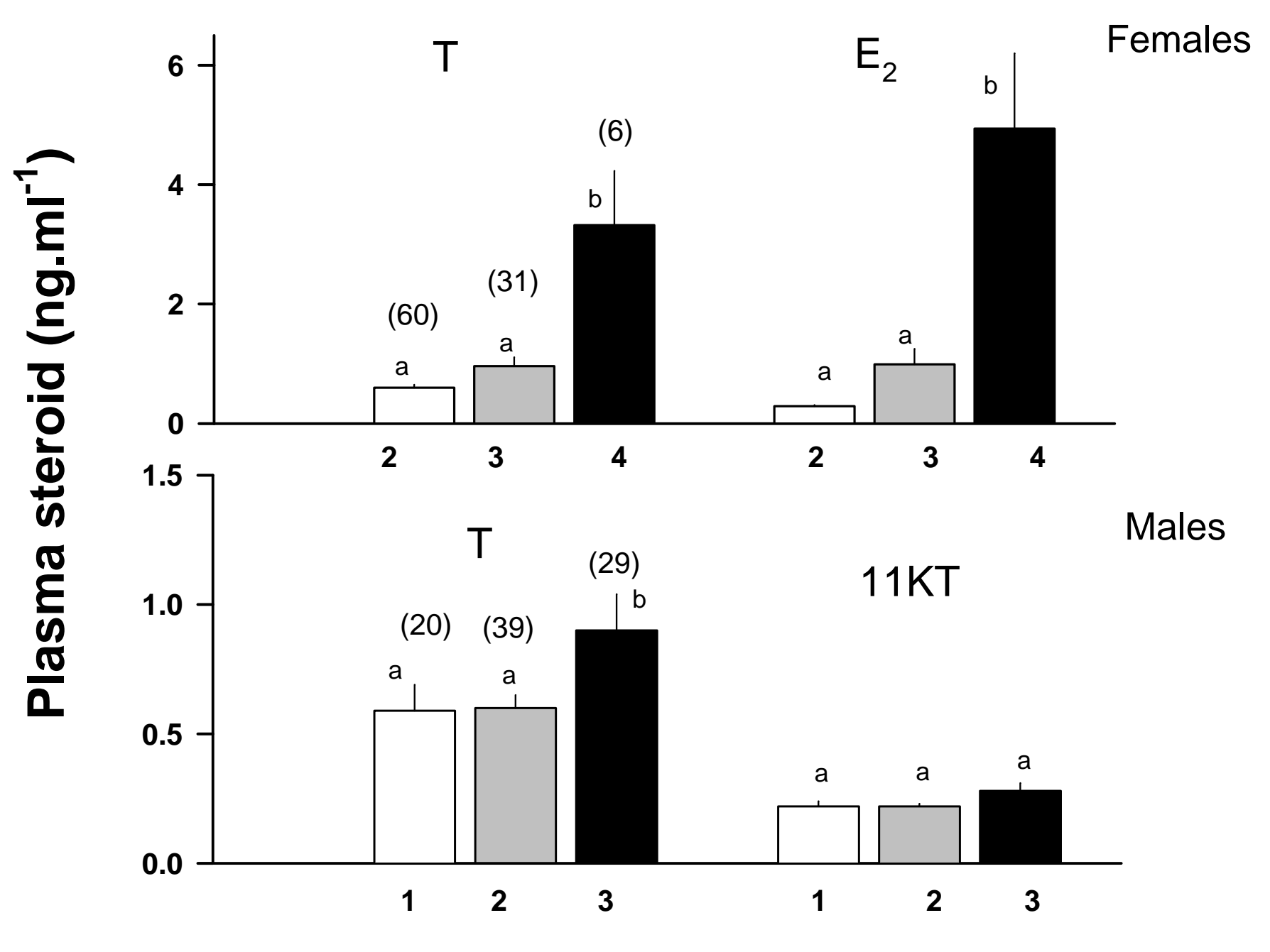

Gonad stage 


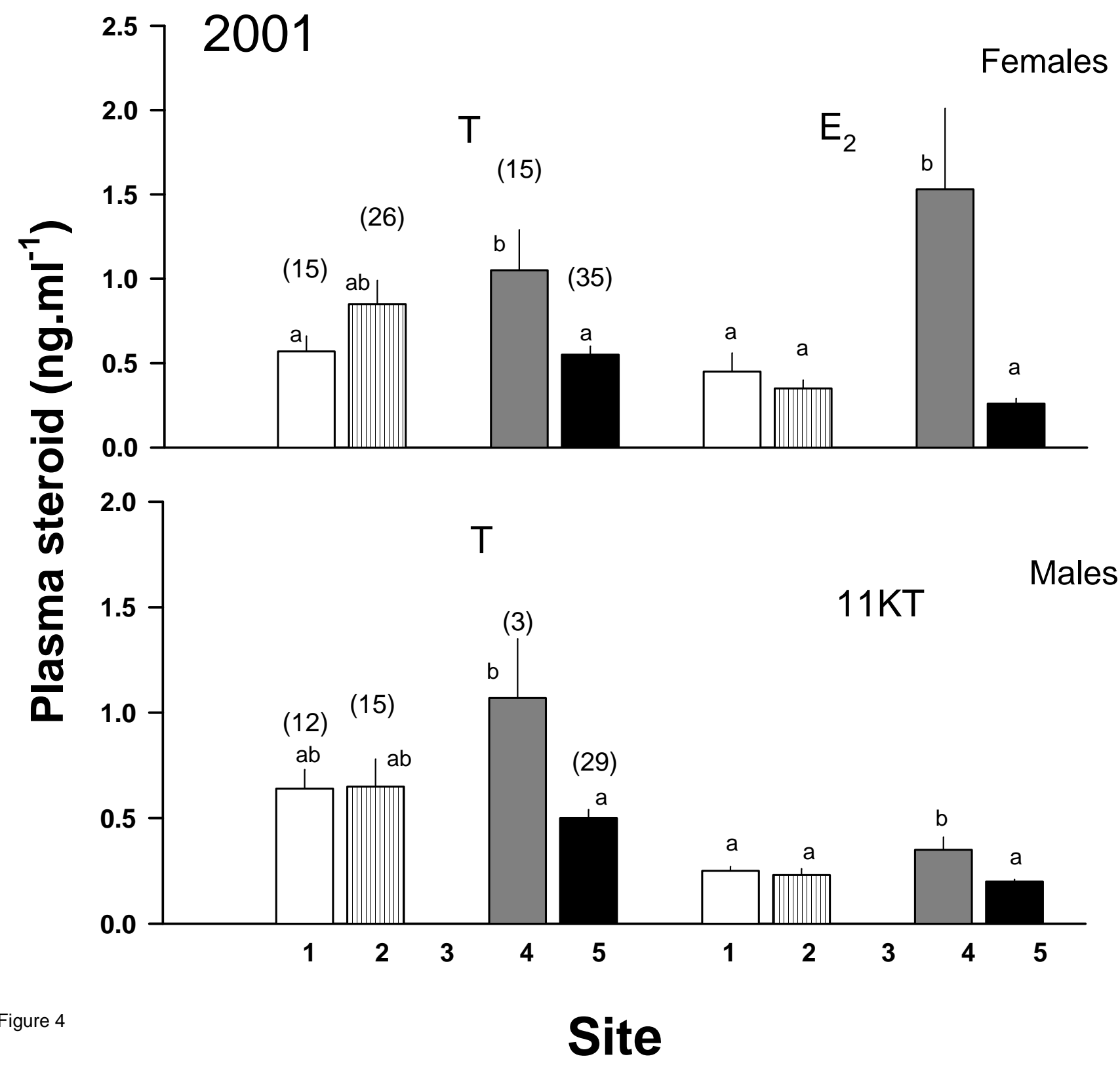




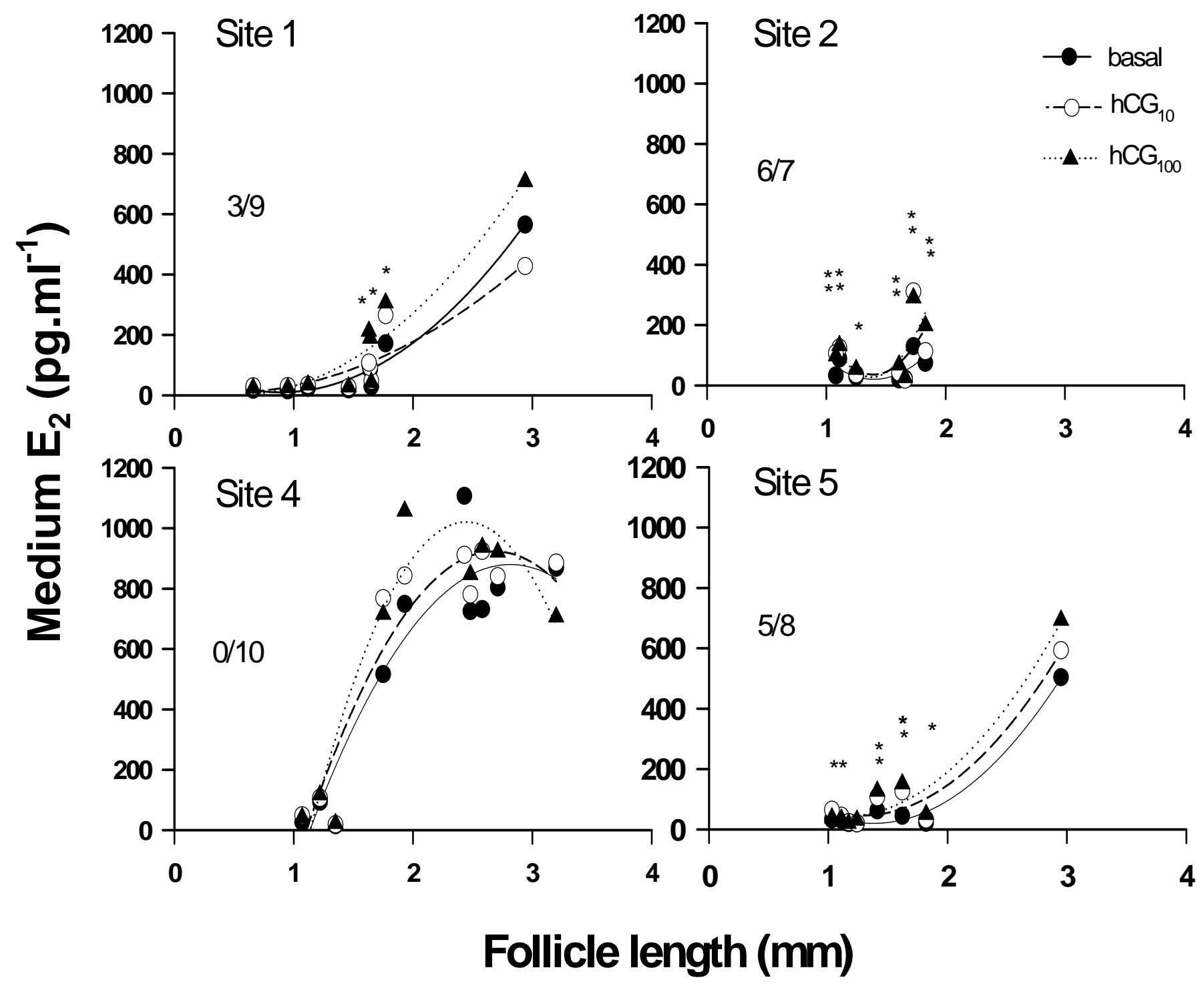

ivrege1 Figure 5 


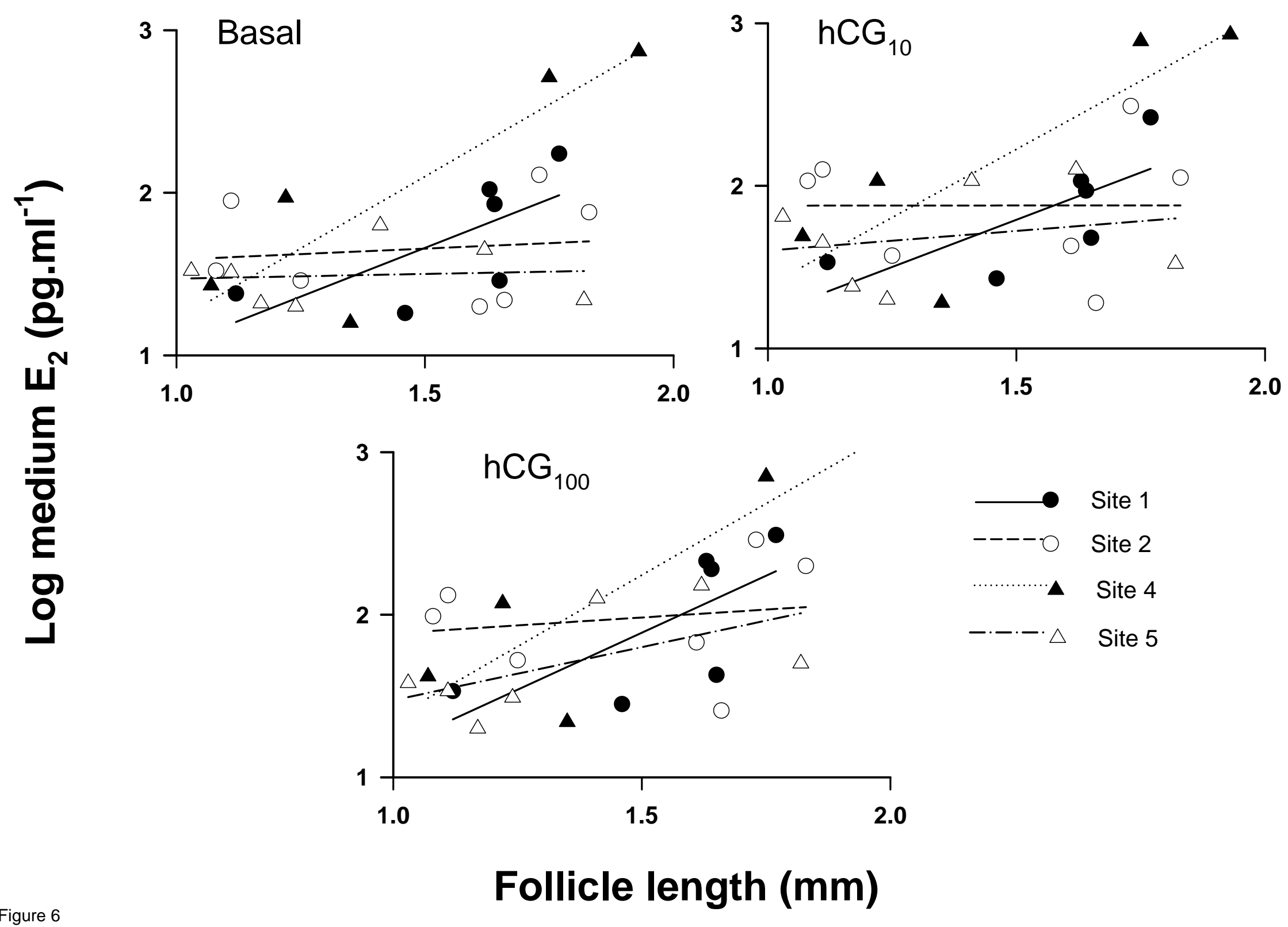



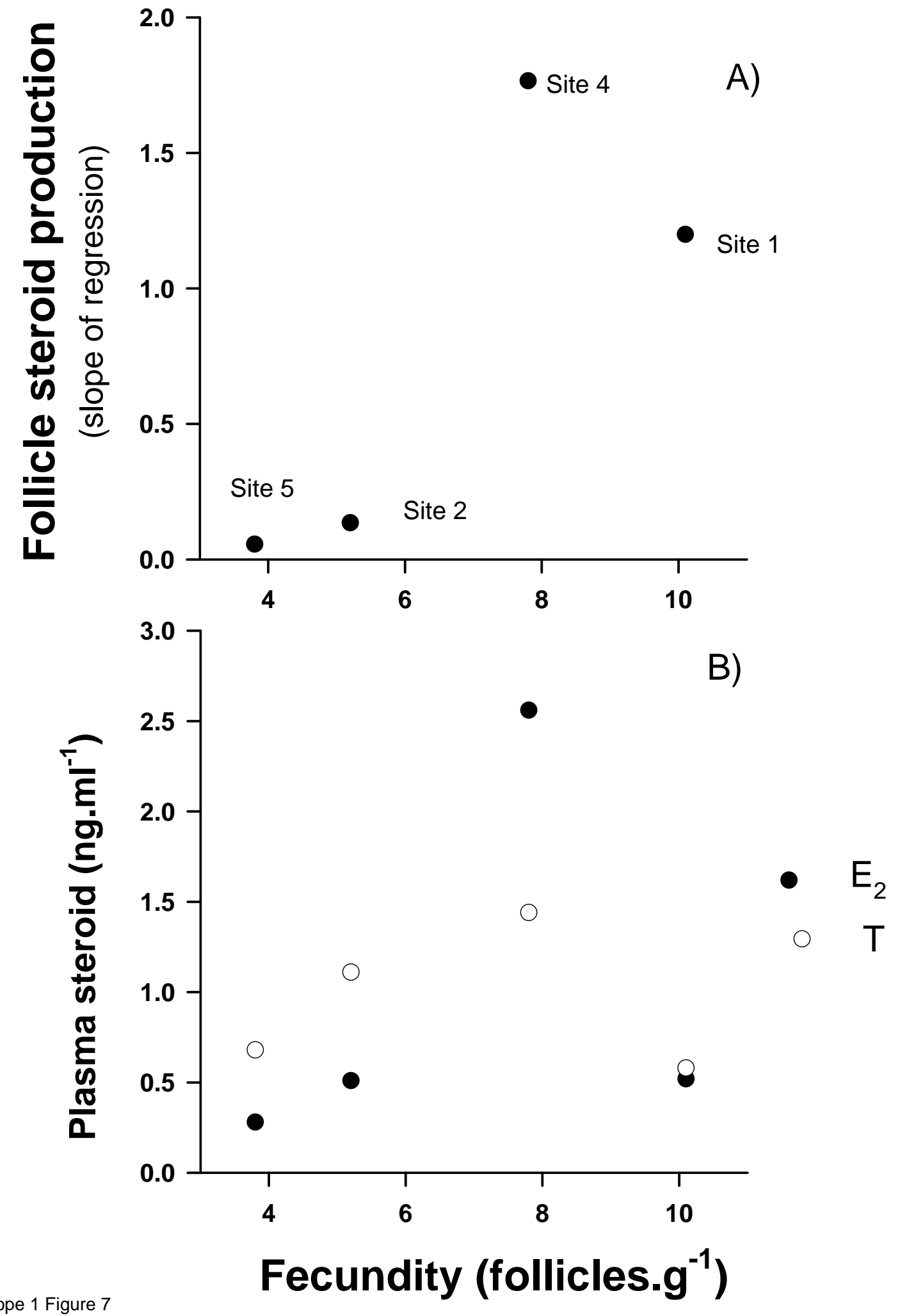